\title{
Aging differentially affects male and female neural stem cell neurogenic properties
}

This article was published in the following Dove Press journal:

Stem Cells and Cloning:Advances and Applications

3I August 2010

Number of times this article has been viewed

Jay Waldron'

Althea McCourty'

Laurent Lecanu', ${ }^{1,2}$

'The Research Institute of the McGill University Health Centre, Montreal,

Canada; ${ }^{2}$ Department of Medicine, McGill University, Montreal, Quebec, Canada
Correspondence: Laurent Lecanu MUHC-RI, 6100 Royalmount Avenue, Montreal H4P 2R2, Quebec, Canada $\mathrm{Tel}+\mathrm{I} 5142458180$

$\mathrm{Fax}+\mathrm{I} 5 \mathrm{I} 2836282$

Email laurent.lecanu@mcgill.ca
Purpose: Neural stem cell transplantation as a brain repair strategy is a very promising technology. However, despite many attempts, the clinical success remains very deceiving. Despite clear evidence that sexual dimorphism rules many aspects of human biology, the occurrence of a sex difference in neural stem cell biology is largely understudied. Herein, we propose to determine whether gender is a dimension that drives the fate of neural stem cells through aging. Should it occur, we believe that neural stem cell sexual dimorphism and its variation during aging should be taken into account to refine clinical approaches of brain repair strategies.

Methods: Neural stem cells were isolated from the subventricular zone of three- and 20-monthold male and female Long-Evans rats. Expression of the estrogen receptors, ER $\alpha$ and ER $\beta$, progesterone receptor, androgen receptor, and glucocorticoid receptor was analyzed and quantified by Western blotting on undifferentiated neural stem cells. A second set of neural stem cells was treated with retinoic acid to trigger differentiation, and the expression of neuronal, astroglial, and oligodendroglial markers was determined using Western blotting.

Conclusion: We provided in vitro evidence that the fate of neural stem cells is affected by sex and aging. Indeed, young male neural stem cells mainly expressed markers of neuronal and oligodendroglial fate, whereas young female neural stem cells underwent differentiation towards an astroglial phenotype. Aging resulted in a lessened capacity to express neuron and astrocyte markers. Undifferentiated neural stem cells displayed sexual dimorphism in the expression of steroid receptors, in particular ER $\alpha$ and ER $\beta$, and the expression level of several steroid receptors increased during aging. Such sexual dimorphism might explain, at least in part, the sex difference in neural fate we observed in young and old neural stem cells. These results suggest that sex and aging are two factors to be taken into consideration for future neural stem cell transplantation protocols in brain repair strategies.

Keywords: neuroregenerative medicine, brain repair strategy, gender difference, stem cell therapy, adult stem cells

\section{Introduction}

Stem cell transplantation and activation of endogenous neurogenesis as approaches to brain repair are at the forefront of neuroregenerative medicine. This particular therapeutic area of neurology and neurosurgery has triggered a great deal of effort in preclinical and clinical research in order to establish relevant and efficient protocols that would lead to clinical success. However, so far, the clinical efficacy of stem cell transplantation in terms of functional recovery remains rather anecdotal, ${ }^{1,2}$ and a reason may be lack of consensus regarding the type of stem cells to be used depending on the patient to 
be treated. In particular, based on the prevailing assumption that male and female neural stem cells are equivalent, gender as a determining factor of the fate of neural stem cells has been largely understudied. As with any mammal, the human being is a sexually dimorphic species. As such, we display sex differences in various physiologic and pathophysiologic processes, ${ }^{3}$ reflecting in this respect the differential effect of the gonadal hormones, estrogens and androgens. Sexual dimorphism has also been described in aging, whether physiologic or pathologic. ${ }^{46}$ However, although there is accumulating evidence on aging-related alteration of neural stem cell neurogenic properties, ${ }^{7}$ whether aging affects differential male and female neural stem cell function remains to be established. Furthermore, there is no reason to believe a priori that male and female neural stem cell capacity to undergo neurogenesis would evolve in a sex-independent manner during aging. Considering the dramatic and gender-specific hormonal changes occurring during aging one could expect a gender-specific, age-related environment to be a prerequisite for successful neural stem cell transplantation and neurogenesis. In the present study, we explored the role of cell sex and age as determining factors of neural fate, followed by differentiating neural stem cells and their relationship to a potential differential expression of steroid receptors during aging.

\section{Material and methods Neural stem cell isolation and amplification}

Male and female 3-month-old and 20-month-old Long-Evans rats were anesthetized with 3\% isoflurane and transcardially perfused with DMEM/F12 medium (Invitrogen, Carlsbad, CA). Following decapitation, brains were removed and rinsed in phosphate-buffered saline/1\% penicillin/streptomycin/ gentamicin (PSG; Invitrogen) before being placed in sterile plastic Petri dishes containing Leibovitz L15 medium (Invitrogen) on ice. Two coronal cuts were made in the area between the rhinal fissure and the hippocampus. The resulting tissue chunk was placed on its posterior surface, and the cortex above the corpus callosum and surrounding the ventricles removed. ${ }^{8}$ The remaining tissue (SVZ) was placed in another sterile Petri dish containing L15 with $2.5 \mathrm{UI} / \mathrm{mL}$ papain (Invitrogen), $10 \mathrm{UI} / \mathrm{mL}$ DNAse I (Invitrogen), 1\% PSG, and diced into approximately $1 \mathrm{~mm}^{3}$ portions. The diced SVZs were each transferred to $50 \mathrm{~mL}$ centrifuge tubes containing $25 \mathrm{~mL} \mathrm{L15}$ media plus $2.5 \mathrm{UI} / \mathrm{mL}$ papain, $10 \mathrm{UI} / \mathrm{mL}$ DNAse I, and $1 \%$ PSG, and allowed to digest for 40 minutes at $37^{\circ} \mathrm{C}$ in a mixer-incubator. Following digestion, the tissue suspensions were centrifuged at $300 \mathrm{rpm}$ for 2 minutes, the pellets were resuspended in $25 \mathrm{~mL}$ Dulbecco's modified Eagle's medium (DMEM) /F12 containing $10 \mathrm{UI} / \mathrm{mL}$ DNAse, $2 \% \mathrm{~B} 27$, and $1 \%$ PSG, and centrifuged at $300 \mathrm{rpm}$ for another two minutes. The supernatants were removed and replaced with $3 \mathrm{~mL} 37^{\circ} \mathrm{C}$ DMEM/F12. Following trituration with a disposable pipette, the homogenates were passed sequentially through $100 \mu \mathrm{m}, 70 \mu \mathrm{m}$, and $40 \mu \mathrm{m}$ cell strainers. The filtered homogenates were then transferred to a $10 \mathrm{~mL}$ centrifuge tube, and the volume was increased to $4.5 \mathrm{~mL}$ with DMEM/F12, to which was added $4.5 \mathrm{~mL}$ Percoll $^{\circledR}$ solution. This mixture was centrifuged at $12,000 \mathrm{rpm}$ at $18^{\circ} \mathrm{C}$ for one hour. Density marker beads (GE Healthcare) were used to determine the layer corresponding to the neural stem cells $(1.065-1.075 \mathrm{~g} / \mathrm{mL}){ }^{9}$ The cells were placed in a sterile $15 \mathrm{~mL}$ centrifuge tube, and rinsed with $15 \mathrm{~mL}$ of DMEM/F12 at $37^{\circ} \mathrm{C}$. Following centrifugation for 10 minutes at $900 \mathrm{rpm}$, $14.5 \mathrm{~mL}$ of supernatant was removed and replaced with $14.5 \mathrm{~mL}$ Neurobasal A (Invitrogen) at $37^{\circ} \mathrm{C}$ containing $2 \%$ B27 (Invitrogen), 2 nM L-glutamine (Thermo Fisher Scientific, Waltham, MA), $20 \mathrm{ng} / \mathrm{mL}$ epidermal growth factor (Invitrogen), $20 \mathrm{ng} / \mathrm{mL}$ fibroblast growth factor-basic (PeproTech, Rocky Hill, NJ) and $2 \mu \mathrm{g} / \mathrm{mL}$ heparin (Sigma, St Louis, MO). The cells were centrifuged for 10 minutes at $900 \mathrm{rpm}$, and resuspended cells were seeded in 6-well low attachment plates (Corning, Avon, France) and incubated at $37^{\circ} \mathrm{C}$. Epidermal growth factor, fibroblast growth factor-basic, and heparin were added to cells three times a week, and culture medium was changed once a week. Neurospheres were split every month using Accumax ${ }^{\circledR}$ (Innovative Cell Tech, San Diego, CA).

\section{Neurosphere differentiation}

Prior to differentiation, neural stem cells were plated and nestin expression was assessed by immunofluorescence using a specific antibody (Abcam, Cambridge, MA) in order to validate the stemness of our samples. Immunostaining was revealed using a secondary antibody DyLight 594 (Jackson Immunoresearch, West Grove, PA). Primary neurospheres were pipetted into glass bottom 6-well plates (MatTek, Ashland, MA) coated with poly-L-ornithine and laminin (Sigma) and treated daily for 10 days with retinoic acid $1 \mu \mathrm{M}$ (Sigma).

\section{Western blotting}

Proteins were extracted using RIPA, and protein concentration was determined (Micro BCA ${ }^{\mathrm{TM}}$ Protein Assay Kit, ThermoScientific). Samples for ER $\alpha$ and ER $\beta$ were separated on a Criterion XT Tris-HCl gel 4\%-20\% with sodium dodecyl 
sulfate/Tris/glycine running buffer, and the other samples were separated on a Criterion XT Bis-Tris gel 4\%-12\% with MES running buffer (Bio-Rad), all under reduced conditions. The gels ran for two hours (ER $\alpha$ and $E R \beta)$ and 1.5 hours (other proteins) at $130 \mathrm{~V}$ and transferred onto $0.45 \mu \mathrm{m}$ nitrocellulose membranes (ER $\alpha$ and $E R \beta)$ or polyvinylidene fluoride membranes (other proteins) for one hour at $65 \mathrm{~A}$ with Tris/ glycine transfer buffer in $20 \%$ methanol. Biotinylated and kaleidoscope markers were included in every run. Membranes were blocked with $1 \mathrm{X}$ casein (Vector Labs, Burlington, ON) and incubated overnight at $4^{\circ} \mathrm{C}$ in primary antibody, then incubated in biotinylated secondary antibody (Cell Signaling Technology, Pickering, ON) at a dilution of 1:1000 for one hour at room temperature. An avidin biotin complex amplification (Vectastain ${ }^{\circledR}$ ABC-AmP ${ }^{\text {TM}}$; Vector Labs) was used and incubated for 10 minutes at room temperature. Membranes were equilibrated in $0.1 \mathrm{M}$ Tris buffer, $\mathrm{pH} 9.5$, and were visualized using chemiluminescence (DuoLuX ${ }^{\mathrm{TM}}$; Vector Labs). The images were detected with an imaging analysis system (ImageQuant 350; GE Healthcare). Undifferentiated neurospheres were assayed for ER $\alpha, E R \beta$, glucocorticoid (Abcam), progesterone, and androgen receptors (Abbiotec, San Diego, $\mathrm{CA}$ ) and differentiated neurospheres were assayed for the neuronal markers $\beta$ III-tubulin, GAP43 (Millipore, Temecula, CA), doublecortin, MAP2 (Cell Signaling Technology), the astrocyte marker GFAP, and the oligodendrocyte marker CNPase (Abcam). Ratio protein of interest over actin or GAPDH (Abcam) was calculated to quantify protein expression. The neural stem cells used in this protocol never underwent more than five passages.

Statistical analysis was conducted by Student's $t$-test using the results obtained with neural stem cells isolated from three different rats for each gender. Results were expressed as mean \pm standard error of measurement.

\section{Results}

\section{Neural stem cell stemness}

The expression of the stem cell marker, nestin, was found to be very important in the four types of neural stem cells, ie, young (Figures 1a and 1b) and old (Figures 1c and 1d), and male (Figures 1a and 1b) and female (Figures 1c and 1d).

\section{Neural marker expression}

In young and old adult animals, the expression of the early neuronal marker, $\beta$ III-tubulin, was found to be equivalent in male and female neural stem cells. However, there was a dramatic decrease of $\beta$ III-tubulin expression in neural stem

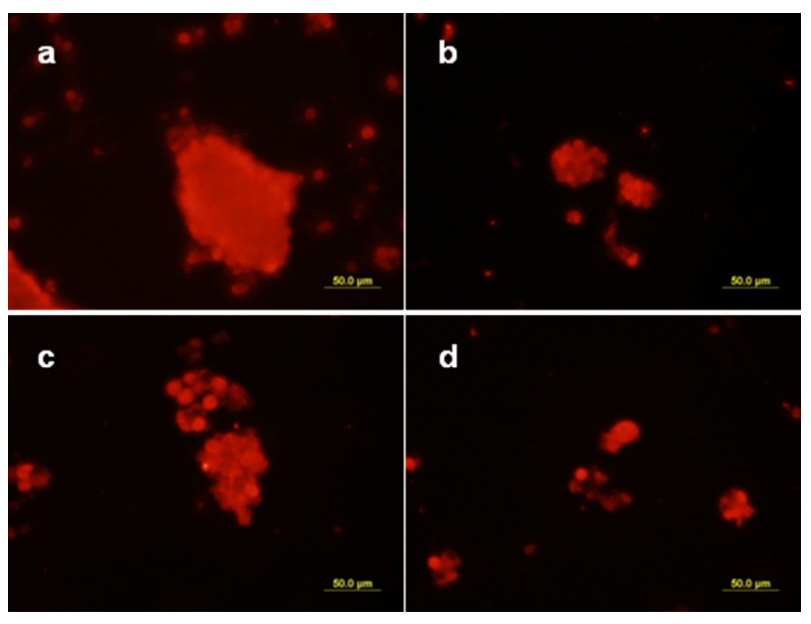

Figure I Nestin expression in neural stem cells. Neural stem cells were plated and their stemness assessed using an antibody raised against the stem cell marker, nestin. a) and b) Three-month-old neural stem cells; c) and d) 20-month-old neural stem cells; a) and b) male neural stem cells; c) and d) female neural stem cells.

cells isolated from old rats compared with those from young rats (Figure 2a). On the other hand, expression of the marker for mature neurons MAP2, growth cones GAP43, and the neuroblast doublecortin were all expressed in higher amounts in neural stem cells isolated from young males than from young females (Figures 2b, 2c, and 2d). As with BIII-tubulin, the expression of these specific markers was much lower in neural stem cells isolated from old rats and not significantly different between the sexes, except for doublecortin expression which was found in larger amounts in male than in female neural stem cells. It is noteworthy that two bands were detected at the MAP2 molecular weight in neural stem cells from young animals, the higher molecular weight most likely corresponding to a phosphorylated form of MAP2 (Figure 2b), whereas only one band (dephosphorylated form) was detected in neural stem cells from old rats. In the same manner, a second band of higher molecular weight and lighter intensity, likely corresponding to a phosphorylated isoform, was detected with doublecortin in differentiated neural stem cells from young female rats (Figure 2d). This second band was detected in only one sample of young male neural stem cells out of three, and was not observed in differentiated neural stem cells isolated from old animals. Neural stem cells from young female rats expressed three times the amount of the astrocyte marker, GFAP, found in male neural stem cells of the same age (Figure 2e). The same marker was barely detectable in 20-month-old animals. The expression of the oligodendrocyte marker, CNPase, showed an opposite pattern compared with GFAP. Neural stem cells isolated from both young male rats showed higher amounts of CNPase than the female counterparts and remained constant in 
a

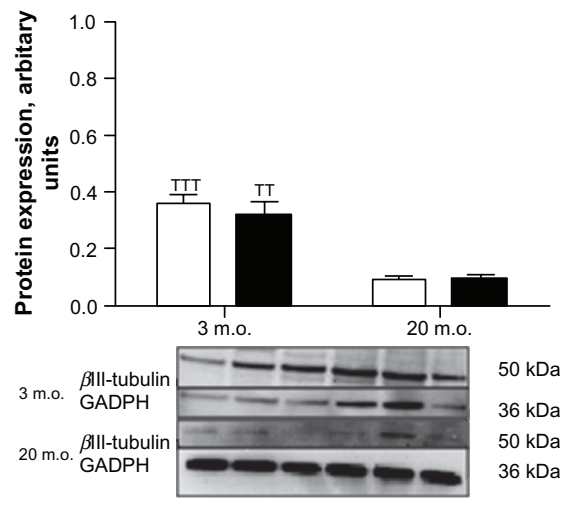

C
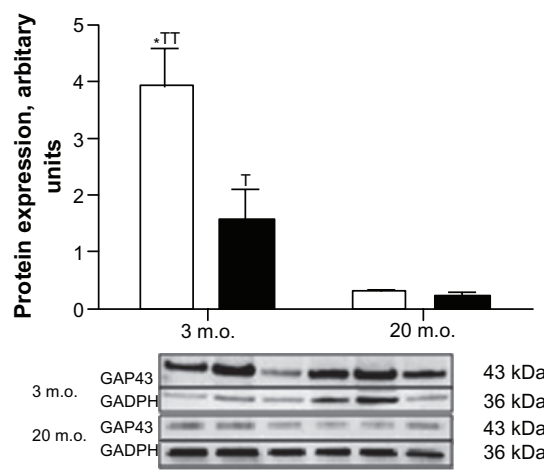

e

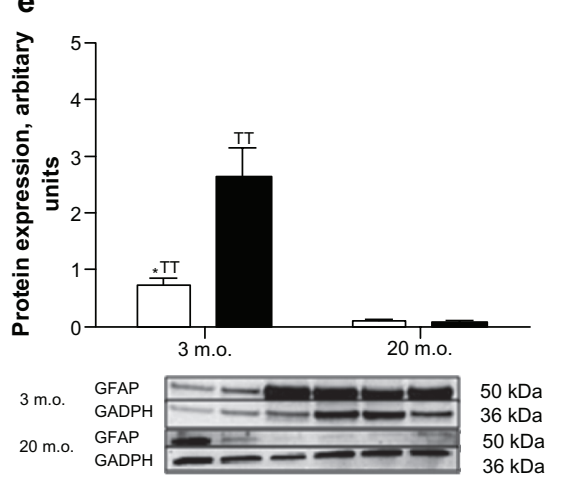

b

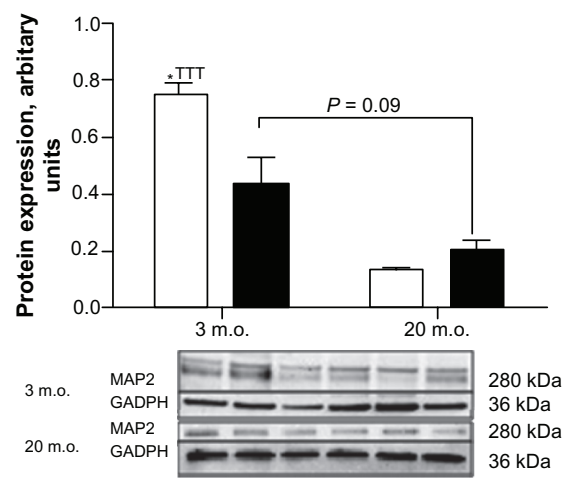

d

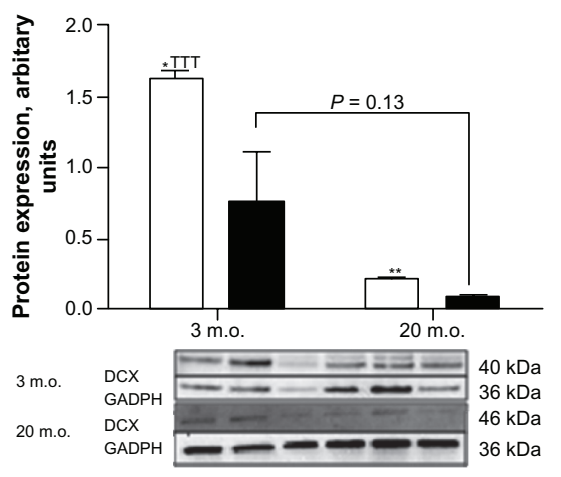

f

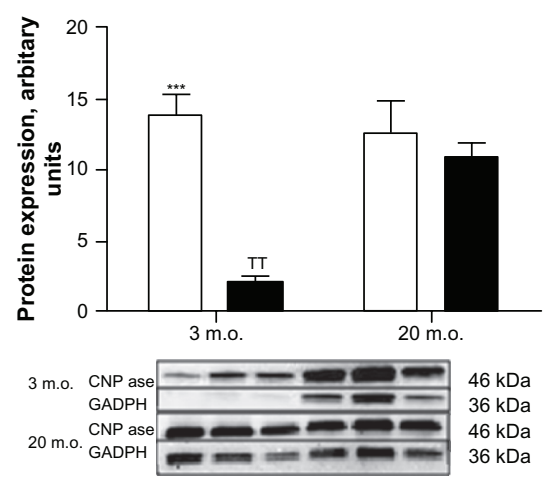

Figure 2 Retinoic acid-induced neural marker expression. Neural stem cells isolated from three- and 20-month-old male (open bars) and female (black bars) rats were grown as neurospheres in serum-free medium and treated with retinoic acid I $\mu \mathrm{M}$ for 10 days. Neurospheres were then harvested, the protein extracted, and the expression of neural fate-specific markers determined by Western blotting. a) Blll-tubulin, b) MAP2, c) GAP43, d) doublecortin, e) GFAP, and f) CNPase. On each gel, the three left lines represent the male samples and the three right lines represent the female samples. Statistical analyses were performed by Student's $t$-test using the results obtained with neural stem cells isolated from three different rats for each sex.

Notes: ${ }^{\top} P<0.05,{ }^{\top T} P<0.01$, ${ }^{\top T T} P<0.001$ comparison versus same sex 20 -month-old neural stem cells. ${ }^{*} P<0.05$, ${ }^{* * * *} P<0.00$ I, comparison versus same-age female neural stem cells. Results are presented as mean \pm standard error of measurement.

old rats. The expression of CNPase in old female neural stem cells was found to be increased compared with young female neural stem cells and was equivalent in old male neural stem cells (Figure 2f).

\section{Steroid receptor expression}

$\mathrm{ER} \alpha$ and $\operatorname{ER} \beta$ were found to be expressed in the same amount in neural stem cells from 3-month-old male rats
(Figures $3 \mathrm{a}$ and $3 \mathrm{~b}$ ), whereas ER $\alpha$ expression was higher in 3-month-old female neural stem cells than that of ER $\beta$. In addition, $\mathrm{ER} \alpha$ expression was higher and $\mathrm{ER} \beta$ expression lower in neural stem cells isolated from young adult female rats than in its male counterparts (Figures $3 a$ and $3 b$ ). Twentymonth-old male and female neural stem cells expressed equivalent amounts of ER $\alpha$ and $E R \beta$, and their expression was found to be dramatically increased compared with neural 


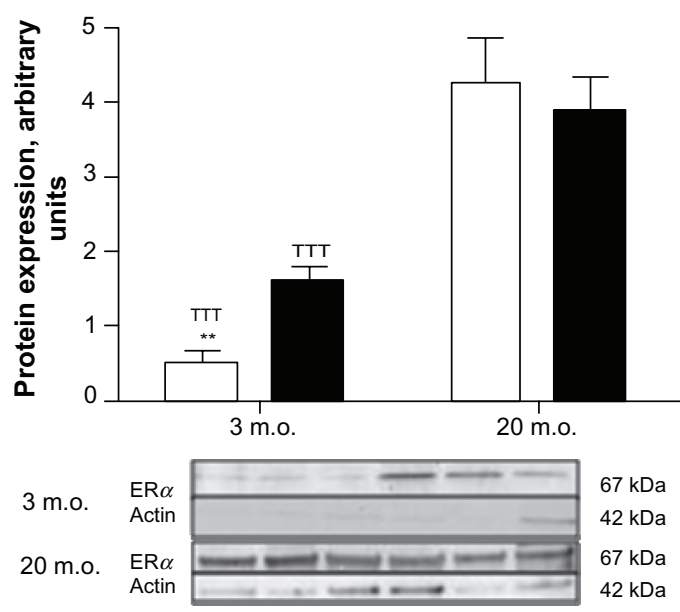

C
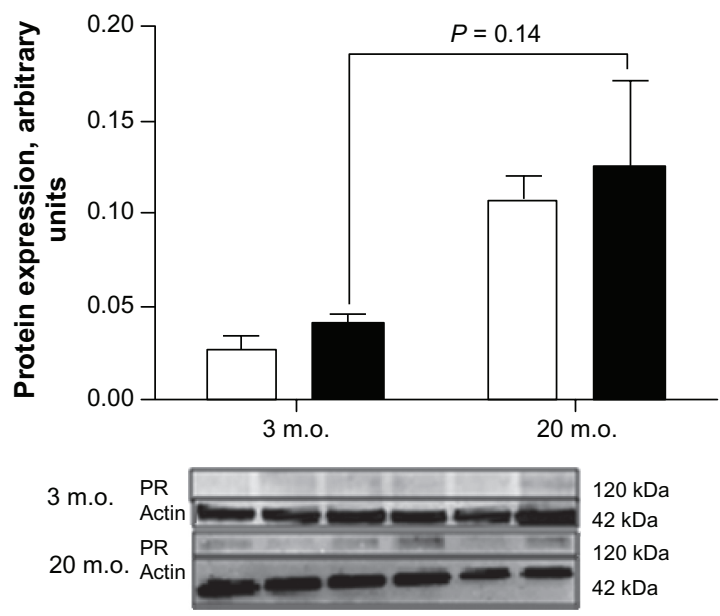

b

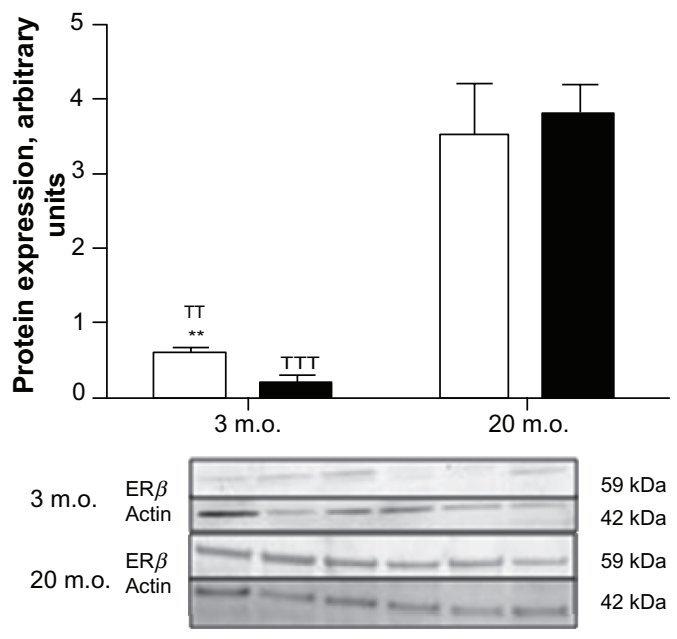

d

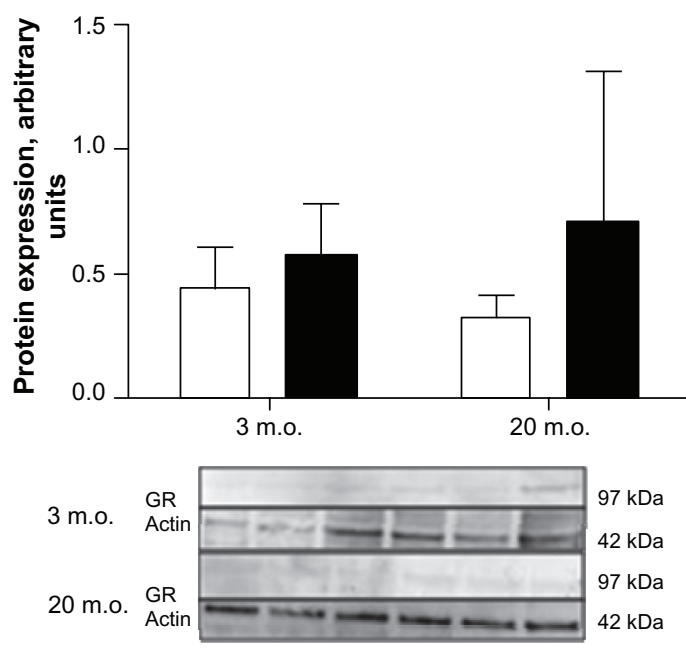

Figure 3 Steroid receptor expression in undifferentiated neural stem cells. Neural stem cells isolated from three- and 20-month-old male (open bars) and female (black bars) rats were grown as neurospheres in serum-free medium. Neurospheres were then harvested, protein extracted, and the expression of steroid receptors determined by Western blotting. On each gel, the three left lines represent the male samples and the three right lines represent the female samples. Statistical analyses were performed by Student's $t$-test using the results obtained with neural stem cells isolated from three different rats for each sex.

Notes: ${ }^{\mathrm{TT}} P<0.0$ I, ${ }^{\mathrm{TTT}} \mathrm{P}<0.00 \mathrm{I}$ comparison versus same sex 20 -month-old neural stem cells. ${ }^{* *} \mathrm{P}<0.00 \mathrm{I}$ comparison versus same age female neural stem cells. Results are presented as mean \pm standard error of measurement.

stem cells isolated from three-month-old male and female rats (Figures $3 \mathrm{a}$ and $3 \mathrm{~b}$ ). The expression of progesterone receptors was found to be similar between neural stem cells isolated from same aged male and female rats; however, this expression was three times higher in old than in young neural stem cells (Figure 2c). No differences were found between glucocorticoid receptor expression in neural stem cells for both sexes and across ages (Figure 3d).

\section{Discussion}

Brain repair and functional recovery after stroke or as a treatment outcome for neurodegenerative disease is a very hot topic and generates a lot of activity in preclinical and clinical research. However, in the lack of consensus as to "what type of stem cell and for whom?", the clinical reality of this therapeutic approach is still a far reach. In the absence of a clear definition of what type of stem cell/progenitor may be used, characterizing adult neural stem cells as a potential source of biologic material for brain repair looked to us to be a fundamental prerequisite to any relevant clinical application. We showed herein that the neurogenic properties of adult male and female neural stem cells are not equivalent, that they are differentially affected by aging, and that this sexual dimorphism of the neural phenotype is associated with 
a sexual dimorphism of the expression of various steroid receptors in undifferentiated neural stem cells.

Sexual dimorphism of the neural phenotype acquired by differentiating neural stem cells exposed to retinoic acid was mainly noticeable with neural stem cells isolated from 3-month-old animals. Indeed, male neural stem cells expressed markers of neuronal fate, ie, MAP2 and GAP43, in higher amounts than their female counterparts. Likewise, the neuroblast marker, doublecortin, was found to be more abundantly expressed in male neural stem cells, suggesting that in our experimental conditions, male neural stem cells were more prone to acquire a neuronal phenotype when stimulated with retinoic acid than the female neural stem cells. It is noteworthy that neurospheres were grown in serumfree conditions in order to prevent any interference from a steroid-related effect. This experimental protocol was sought to guarantee a neutral "sexless" environment that would allow detection of phenotypic differences that would be intrinsic to neural stem cells and not due to environmental conditions. Interestingly, the opposite expression pattern was observed with GFAP, because female neural stem cells displayed a fourfold expression level of the astrocyte marker compared with the male neural stem cells. In addition, GFAP was the neural marker expressed with the highest "over GAPDH" ratio by female neural stem cells suggesting that, unlike male neural stem cells, female neural stem cells were rather directed towards an astroglial fate, therefore demonstrating a clear sexual dimorphism. Quantification of the expression of the oligodendrocyte marker, CNPase, showed that this protein was expressed in higher amounts in male differentiating neurospheres, suggesting that oligodendrocyte progenitors present in male neurospheres are more prone to differentiate in the mature phenotype than females. We hypothesized that male neural stem cells, being more prone to differentiate towards a neuronal fate, would require a denser oligodendroglial phenotype subset in order to supply the myelin sheaths necessary for functional neuronal growth. Interestingly, a recent in vivo study reported sexual dimorphism of oligodendrocytes and myelin protein expression in rat brain, oligodendrocytes being more numerous and more densely packed, and myelin protein expression being greater in male brains than in female brains. ${ }^{10}$ The same laboratory provided evidence that such a dimorphism was not related to environmental difference, but was instead intrinsic to the progenitor cells and due to a differential regulatory pathway. ${ }^{11}$

Our results are supported by recent data showing that such gender-based stem cell determinism exists in striated muscle. Indeed, the cell sex as a variable that considerably affects the capacity of muscle-derived stem cells to regenerate tissue has been recently proposed, because female musclederived stem cells have been reported to have higher muscle regeneration efficiency than their male counterparts. ${ }^{12,13}$ Furthermore, sex and age have recently been demonstrated to influence the chondrogenic potential of human femoral bone marrow stem cells. ${ }^{14}$

In addition, one cannot rule out that the difference in the phenotype acquired by male and female differentiating neural stem cells may be due to a sex-based differential reactivity to retinoic acid. Retinoic acid is a member of the steroid/ thyroid superfamily of signalling molecules, and its role in brain morphogenesis, differentiation, and regeneration is very well described, and its neurogenic properties have been extensively studied. ${ }^{15-17}$ However, to our knowledge, such sex-driven differential pharmacology has never been reported, and further work is required to determine its biologic reality and its potential impact on future clinical applications.

The sexual dimorphism observed in the differentiating neural stem cells isolated from young adult rats was much less remarkable in the differentiating neural stem cells isolated from 20-month-old rats. Indeed, the dramatic decrease in expression of the neuronal markers, $\beta$ III-tubulin, MAP2, and GAP43, was found to be a common pattern displayed by male and female differentiating aging neural stem cells, at a level that was equivalent for both sexes. However, the expression of the neuroblast marker, doublecortin, although lower for both old male and female neural stem cells, remained significantly higher in the differentiating 20-month-old male neural stem cells than in the female ones, suggesting that aging male neural stem cells might retain neurogenic properties over a longer period of time than aging females neural stem cells. Decreased neurogenesis associated with aging has been documented, ${ }^{7}$ but it is still unclear whether it is because the aging brain possesses less progenitors, although they retain their full capacity to proliferate and differentiate, ${ }^{18}$ or because, although the aging brain has the same number of progenitors, these cells have a diminished capacity to integrate in a functional manner in the existing neuronal network. ${ }^{19}$

Nevertheless, taken together, our results suggest that old male neural stem cells, unlike female ones, remain more responsive to neurogenic stimuli regardless of the mechanism by which neurogenesis is decreased during aging, and displaying a clear sex-based difference in this respect. A decrease of retinoic acid pathway activity, as well as a decrease of retinoic acid receptor expression, has been described in the aging brain and proposed to contribute to cognitive decline in healthy aging. ${ }^{20-22}$ Although our experimental protocol 
did not allow us to investigate such biochemical alteration, an hypoactive retinoic acid pathway might also explain the lessened responsiveness of 20-month-old neural stem cells to retinoic acid stimulation compared with the 3-month-old neural stem cells. The low level of GFAP expression observed in differentiating 20-month-old neural stem cells suggested that old neural stem cells, regardless of sex, retained only little capacity to undergo astroglial differentiation. Endogenous retinoic acid is produced in the central nervous system by astrocytes ${ }^{23}$ which makes astrocytes a major supporting cell type for neurogenesis. Therefore, this specific point raises the question of the appropriateness of using old neural stem cells as biologic material for transplantation because they would not be able to generate the necessary supporting astroglial cells which, in turn, would prevent the supply of endogenous retinoic acid. Unlike the neuronal and astroglial markers, the expression of the oligodendrocyte marker, CNPase, did not decrease with aging. Instead, old differentiating male neural stem cells were found to maintain the same level of CNPase expression as in young neural stem cells, and CNPase expression dramatically increased in old differentiating female neural stem cells compared with young ones to reach the same levels found in old male neural stem cells. We hypothesized that maintaining or increasing oligodendrocyte formation would allow old brain to sustain sheath formation and neuron repair activity, which is supported by a recent study reporting that oligodendrogenesis and myelin production are increased in old mice brain. ${ }^{24}$

Sexual dimorphism has been also observed in vivo in the remyelinizating capacity of the central nervous system. ${ }^{25}$ The authors showed that following a demyelinizating lesion of the cerebellum, whereas no difference was observed between young adult male and female rats, old female rats remyelinized faster and better than the males. This oligodendrogenesis dynamic supports the increased CNPase expression we observed in neural stem cells isolated from 20-month-old females.

We observed that differentiated neural stem cells isolated from young animals expressed both the dephosphorylated and phosphorylated MAP2 isoforms independently of sex. MAP2 phosphorylation has been demonstrated to be essential to dendritogenesis and the formation of synapses in newly formed neurons. ${ }^{26,27}$ The same authors showed that the balance between kinases and phosphatase activity was essential to neuron sprouting. ${ }^{26,27}$ Interestingly, the neural stem cells isolated from old rats did not express the MAP2 phosphorylated isoform, suggesting that, unlike young neural stem cells, neurons generated from old neural stem cells may have limited sprouting and synaptogenesis capacities. In the same manner, neuroblasts generated from young female neural stem cells expressed both dephosphorylated and phosphorylated doublecortin at a much higher amount than their male counterparts, whereas no phosphorylated doublecortin was detected in the neuroblasts generated by old neural stem cells. Since the dynamic of doublecortin phosphorylation/dephosphorylation has been described to be responsible for neuroblasts migration and that inhibition of doublecortin phosphorylation inhibits neuronal migration, ${ }^{28,29}$ our results suggest that young female neuroblasts retain better migratory properties than young male neuroblasts. In addition, it also suggests that old neural stem cells, regardless of the sex, in addition to having less capacity to form neuroblasts, might generate neuroblasts that will not be able to complete the neurogenesis process because of their incapacity to migrate through brain tissue.

Debating about sex/gender differences cannot be undertaken without mentioning the gonadal hormones since it is so far the common understanding that they are, by necessity, involved in every aspect of sex dimorphism. In order to determine if a differential dynamic of the steroid pathway could be a basis for neural stem cell sex-based difference, we quantified the expression of various steroid receptors in undifferentiated neurospheres. Male and female neural stem cells, young and old, expressed significant levels of both ER $\alpha$ and ER $\beta$. This set of data is supported by previous results that showed the expression of ER $\alpha$ and ER $\beta$ mRNA in neural stem cells of the SVZ. ${ }^{30}$ Interestingly, neural stem cells isolated from 3-month-old rats display sexual dimorphism in the expression of both estradiol receptor subtypes. Indeed, it was found that young male neural stem cells expressed one third of the ER $\alpha$ amount, whereas ER $\beta$ were found at an amount three times higher than that expressed by the same age female neural stem cells. In addition, the ratio $E R \alpha / E R \beta$ was close to one in the male and equal to 10 in the female neural stem cells. Our results are supported by previous data showing that steroid receptor expression in the fish inner ear varies with sex. ${ }^{31}$ Such sexual dimorphism has also been previously described in mature neurons of various brain structures ${ }^{32,33}$ and has been shown to have a role in the differentiation of sexual behavior and gender identity, ${ }^{34} \mathrm{ER} \alpha$ being primarily involved in masculinization whereas ER $\beta$ is primarily involved in defeminisation. ${ }^{35,36}$ Interestingly, neural stem cells isolated from 20-month-old neural stem cells, male and female, displayed a dramatic increase of ER $\alpha$ and ER $\beta$ expression which was found to be equivalent in both sexes. Such an increase of estrogen receptor expression might reflect a compensatory effect to the decrease of circulating estrogen 
concentration that occurs during aging. Although the effect of estrogens on neural stem cell proliferation and differentiation has already been described, ${ }^{37}$ further studies will be required to clarify the physiologic meaning of the sexual dimorphism of expression of estrogen receptor subtypes that we observed. The significant variability of estrogen receptor expression, depending on the sex and age of the neural stem cells, likely suggests that these neural stem cell groups would respond differently when placed in an identical environment.

This last point raises the fundamental question of neural stem cell selection for clinical applications, because neural stem cells will have to be optimized to respond adequately to the hormonal status of the patient. Progesterone is another important steroid that has been shown, like estrogens, to be involved in neurogenesis, synaptic plasticity, and brain repair. ${ }^{38,39}$ No difference was observed in the expression of progesterone receptors between male and female neural stem cells. However, like estrogen receptors, progesterone receptor expression was significantly increased in old neural stem cells compared with young ones. Progesterone has been described to increase myelinization and sheath formation, as well as to increase the number of oligodendrocytes in brain tissue. ${ }^{40,41}$ In this respect, an increase of progesterone receptors in old neural stem cells reinforces the validity of our results, showing an increase of CNPase expression in differentiating old neural stem cells. Indeed, we could hypothesize that increased expression of progesterone receptors would orientate old neural stem cells preferentially towards an oligodendroglial fate, supporting the increased myelin/oligodendrocyte dynamic previously described in aged brains. ${ }^{24}$ It is noteworthy that we were not able to detect any androgen receptor expression, either in male or in female neural stem cells (data not shown), which suggests that testosterone might not act directly on progenitor cells present in the SVZ, but rather through its aromatized metabolite, estradiol. Our results are supported by previously characterized aromatase expression in progenitor cells of the ventricular layer of the zebra fish forebrain. ${ }^{42}$ In addition, glucocorticoid receptor expression did not seem to differ between male and female neural stem cells and during aging, suggesting that neurogenesis glucocorticoid-dependent repressor input ${ }^{43}$ remains steady throughout aging.

\section{Conclusion}

Our results provide in vitro evidence that sex and aging are two factors that critically affect neural stem cell fate. We have also shown that the sex-based difference in neural fate acquired by differentiating neural stem cells throughout aging correlates with a differential expression of various steroid receptors during the undifferentiated stage that most likely modulates the response of neural stem cells to circulating and locally produced steroids. The effect of sex and aging on the capacity of neural stem cells to undergo differentiation is largely underestimated and understudied, and requires further investigation in order to unravel its biologic significance. Such consideration is of importance because it may dramatically impact development of future protocols in neuroregenerative medicine and brain repair strategies.

\section{Acknowledgments}

This work was funded by the Royal Victoria Hospital Award and by the Canadian Institutes of Health Research Catalyst Grant IAP 92827.

\section{Disclosure}

The authors report no conflicts of interest in this work.

\section{References}

1. Janowski M, Date I. Systemic neurotransplantation-a problem-oriented systematic review. Rev Neurosci. 2009;20:39-60.

2. Krystkowiak P, Gaura V, Labalette M, et al. Alloimmunisation to donor antigens and immune rejection following foetal neural grafts to the brain in patients with Huntington's disease. PLoS One. 2007;2:e166.

3. Gold JH. Gender differences in psychiatric illness and treatments: A critical review. J Nerv Ment Dis. 1998;186:769-775.

4. Baylis C. Sexual dimorphism, the aging kidney, and involvement of nitric oxide deficiency. Semin Nephrol. 2009;29:569-578.

5. Kalichman L, Guermazi A, Li L, et al. Association between age, sex, BMI and CT-evaluated spinal degeneration features. $J$ Back Musculoskelet Rehabil. 2009;22:189-195.

6. Manson NA, Goldberg EJ, Andersson GB. Sexual dimorphism in degenerative disorders of the spine. Orthop Clin North Am. 2006;37: 549-553.

7. Galvan V, Jin K. Neurogenesis in the aging brain. Clin Interv Aging. 2007;2:605-610.

8. Laywell ED, Kukekov VG, Suslov O, et al. Production and analysis of neurospheres from acutely dissociated and postmortem CNS specimens. Methods Mol Biol. 2002;198:15-27.

9. Richardson RM, Holloway KL, Bullock MR, et al. Isolation of neuronal progenitor cells from the adult human neocortex. Acta Neurochir (Wien). 2006;148:773-777.

10. Cerghet M, Skoff RP, Swamydas M, et al. Sexual dimorphism in the white matter of rodents. J Neurol Sci. 2009;286:76-80.

11. Swamydas M, Bessert D, Skoff R. Sexual dimorphism of oligodendrocytes is mediated by differential regulation of signaling pathways. J Neurosci Res. 2009;87:3306-3319.

12. Deasy BM, Lu A, Tebbets JC, et al. A role for cell sex in stem cellmediated skeletal muscle regeneration: Female cells have higher muscle regeneration efficiency. J Cell Biol. 2007;177:73-86.

13. Deasy BM, Schugar RC, Huard J. Sex differences in muscle-derived stem cells and skeletal muscle. Crit Rev Eukaryot Gene Expr. 2008;18: 173-188.

14. Payne KA, Didiano DM, Chu CR. Donor sex and age influence the chondrogenic potential of human femoral bone marrow stem cells. Osteoarthritis Cartilage. 2010;18:705-713.

15. Lane MA, Bailey SJ. Role of retinoid signalling in the adult brain. Prog Neurobiol. 2005;75:275-293. 
16. Matsumoto T, Kubo S, Meszaros LB, et al. The influence of sex on the chondrogenic potential of muscle-derived stem cells: Implications for cartilage regeneration and repair. Arthritis Rheum. 2008;58:3809-3819.

17. Rawson NE, LaMantia AS. Once and again: Retinoic acid signaling in the developing and regenerating olfactory pathway. J Neurobiol. 2006; 66:653-676.

18. Ahlenius H, Visan V, Kokaia M, et al. Neural stem and progenitor cells retain their potential for proliferation and differentiation into functional neurons despite lower number in aged brain. J Neurosci. 2009;29: 4408-4419.

19. Aizawa K, Ageyama N, Terao K, et al. Primate-specific alterations in neural stem/progenitor cells in the aged hippocampus. Neurobiol Aging. Feb 5, 2009. [Epub ahead of print].

20. Enderlin V, Pallet V, Alfos S, et al. Age-related decreases in mRNA for brain nuclear receptors and target genes are reversed by retinoic acid treatment. Neurosci Lett. 1997;229:125-129.

21. Feart C, Pallet V, Boucheron C, et al. Aging affects the retinoic acid and the triiodothyronine nuclear receptor mRNA expression in human peripheral blood mononuclear cells. Eur J Endocrinol. 2005;152:449-458.

22. Redzic ZB, Preston JE, Duncan JA, et al. The choroid plexus-cerebrospinal fluid system: From development to aging. Curr Top Dev Biol. 2005;71:1-52.

23. Kornyei Z, Gocza E, Ruhl R, et al. Astroglia-derived retinoic acid is a key factor in glia-induced neurogenesis. FASEB J. 2007;21:2496-2509.

24. Lasiene J, Matsui A, Sawa Y, et al. Age-related myelin dynamics revealed by increased oligodendrogenesis and short internodes. Aging Cell. 2009;8:201-213.

25. Li WW, Penderis J, Zhao C, et al. Females remyelinate more efficiently than males following demyelination in the aged but not young adult CNS. Exp Neurol. 2006;202:250-254.

26. Chen JR, Wang YJ, Tseng GF. The effect of epidural compression on cerebral cortex: A rat model. J Neurotrauma. 2003;20:767-780.

27. Chen LJ, Wang YJ, Tseng GF. Compression alters kinase and phosphatase activities and tau and MAP2 phosphorylation transiently while prompting the fast adaptive dendritic remodeling of underlying cortical neurons. J Neurotrauma. 2010 Jun 23. [Epub ahead of print].

28. Gdalyahu A, Ghosh I, Levy T, et al. DCX, a new mediator of the JNK pathway. EMBO J. 2004;23:823-832.

29. Shmueli A, Gdalyahu A, Sapoznik S, et al. Site-specific dephosphorylation of doublecortin (DCX) by protein phosphatase 1 (PP1). Mol Cell Neurosci. 2006;32:15-26.
30. Brannvall K, Korhonen L, Lindholm D. Estrogen-receptor-dependent regulation of neural stem cell proliferation and differentiation. Mol Cell Neurosci. 2002;21:512-520.

31. Maruska KP, Fernald RD. Steroid receptor expression in the fish inner ear varies with sex, social status, and reproductive state. BMC Neurosci. 2010;11:58

32. Yamada S, Noguchi D, Ito $H$, et al. Sex and regional differences in decrease of estrogen receptor alpha-immunoreactive cells by estrogen in rat hypothalamus and midbrain. Neurosci Lett. 2009;463:135-139.

33. Zhang JQ, Cai WQ, Zhou DS, et al. Distribution and differences of estrogen receptor beta immunoreactivity in the brain of adult male and female rats. Brain Res. 2002;935:73-80.

34. Hisasue S, Seney ML, Immerman E, et al. Control of cell number in the bed nucleus of the stria terminalis of mice: Role of testosterone metabolites and estrogen receptor subtypes. J Sex Med. 2010;7:1401-1409.

35. Kudwa AE, Bodo C, Gustafsson JA, et al. A previously uncharacterized role for estrogen receptor beta: Defeminization of male brain and behavior. Proc Natl Acad Sci U S A. 2005;102:4608-4612.

36. Kudwa AE, Michopoulos V, Gatewood JD, et al. Roles of estrogen receptors alpha and beta in differentiation of mouse sexual behavior. Neuroscience. 2006;138:921-928.

37. Martinez-Cerdeno V, Noctor SC, Kriegstein AR. Estradiol stimulates progenitor cell division in the ventricular and subventricular zones of the embryonic neocortex. Eur J Neurosci. 2006;24:3475-3488.

38. Brinton RD, Thompson RF, Foy MR, et al. Progesterone receptors: Form and function in brain. Front Neuroendocrinol. 2008;29:313-339.

39. Foy MR, Baudry M, Akopian GK, et al. Regulation of hippocampal synaptic plasticity by estrogen and progesterone. Vitam Horm. 2010;82: 219-239.

40. Labombarda F, Gonzalez SL, Lima A, et al. Effects of progesterone on oligodendrocyte progenitors, oligodendrocyte transcription factors, and myelin proteins following spinal cord injury. Glia. 2009;57:884-897.

41. Schumacher M, Sitruk-Ware R, de Nicola AF. Progesterone and progestins: Neuroprotection and myelin repair. Curr Opin Pharmacol. 2008;8:740-746

42. Pellegrini E, Mouriec K, Anglade I, et al. Identification of aromatasepositive radial glial cells as progenitor cells in the ventricular layer of the forebrain in zebrafish. J Comp Neurol. 2007;501:150-167.

43. Yu S, Patchev AV, Wu Y, et al. Depletion of the neural precursor cell pool by glucocorticoids. Ann Neurol. 2010;67:21-30.
Stem Cells and Cloning: Advances and Applications

\section{Publish your work in this journal}

Stem Cells and Cloning: Advances and Applications is an international, peer-reviewed, open access journal. Areas of interest in stem cell research include: Embryonic cell stems; Adult stem cells; Blastocysts; Cordblood stem cells; Stem cell transformation and culture; Therapeutic cloning; Umbilical cord blood and bone marrow cells; Laboratory,

\section{Dovepress}

animal and human therapeutic studies; Philosophical and ethical issues related to stem cell research. This journal is indexed on CAS. The manuscript management system is completely online and includes a quick and fair peer-review system. Visit http://www.dovepress.com/ testimonials.php to read real quotes from published authors. 